\title{
Alocação do Tempo para Estudo e Desempenho no Vestibular: evidências a partir da Universidade Federal da Bahia
}

\author{
CLÁUDIO PONDÉ AVENA ${ }^{1}$ \\ Doutorando em Educação (UFBA/FACED) \\ Mestre em Economia (UFBA/CME) \\ Professor da Faculdade Ruy Barbosa \\ cpavena@atarde.com.br
}

\begin{abstract}
Resumo
Este artigo desenvolve um modelo teórico acerca do comportamento do vestibulando e um modelo empírico de função de produção educacional. A hipótese básica do artigo, e que se confirma empiricamente, é a de que o indivíduo realiza uma auto-seleção ao escolher o curso para o qual se candidata. Os indivíduos pobres, ou seja, aqueles que têm escassez de tempo para estudar porque trabalham, selecionam os cursos menos concorridos de modo a aumentar as suas chances de ingressar no ensino superior. Uma vez que a concorrência é maior quanto maior for a renda vitalícia promovida pela profissão escolhida, o indivíduo mais pobre perpetua a sua condição de pobreza ao tender a escolher o curso menos concorrido. Isto demonstra a discriminação do vestibular contra os pobres, configurando-se em um mecanismo de seleção bastante injusto socialmente e que promove ainda mais a desigualdade social já tão grande no País.

Palavras-chave: vestibular, tempo para estudo, produção educacional, oportunidades educacionais, desigualdade de renda, estrutura de classes sociais.
\end{abstract}

\section{Resumen}

Este artículo desenvuelve un modelo teórico sobre el comportamiento del estudiante que hace el exámen de ingreso y un modelo empírico de función de producción educacional. La hipótesis básica del artículo es que el candidato a una plaza en la enseñanza superior realiza una auto selección al elegir la carrera para la cual se candidata. Esta hipótesis se confirma empíricamente. Los candidatos pobres, aquellos que tienen poco tiempo para el estudio porque trabajan, prefieren los cursos menos concurridos para aumentar sus posibilidades de ingresar en la enseñanza superior. Una vez que la concurrencia es mayor, cuanto mas

1 Desejo agradecer ao meu orientador, Prof. Dr. Robert E. Verhine, por ter possibilitado o meu acesso à base de dados do Vestibular da UFBA e pelo incentivo para que realizasse este Doutorado; ao Prof. Dr. José Carrera Fernandez pelos comentários a uma versão preliminar deste artigo; aos funcionários da UFBA/CPD, Antônio Ribeiro e Cora Maria, pela boa vontade com que atenderam às minhas solicitações desses dados, e à Faculdade Ruy Barbosa pelo apoio institucional, o que tem possibilitado esta pesquisa. Como de praxe, eventuais erros neste trabalho são de minha inteira responsabilidade. Comentários e sugestões sobre este artigo são bem vindos. Favor enviá-los para o endereço eletrônico. 
elevada es la renta vitalicia promovida por la profesión elegida, el individuo mas pobre eterniza su condición de pobreza al tender a elegir el curso menos concurrido. Esto demuestra que el exámen de ingreso discrimina a los pobres y se configura como un mecanismo de selección bastante injusto socialmente, contribuyendo mas aún a desenvolver la desigualdad social, que ya es elevada en el País.

Palabras-clave: exámen de ingreso, tiempo para el estudio, producción educacional, oportunidades educacionales, desigualdad del ingreso, estructuras de clases sociales.

\begin{abstract}
This paper develops a theoretical behavior model of the student who intends to take the university entrance exam, the "Vestibular", and an empirical model of the educational production function. The basic hypothesis of the article is that there is a self-selection by the student as he/she chooses his/her major field of study. The poorer students, that is, those who have little time to study, tend to choose the less competitive courses as a way to increase their probabilities of entrance. Since it has been observed that the more competitive the course, the higher the lifetime income, it is possible to conclude that the "Vestibular" discriminates against the poor people and thus serves as a mechanism for reinforcing social inequalities in Brazil.

Key words: "vestibular", study time allocation, educational production, educational opportunities, income inequality, social class structure.
\end{abstract}




\section{INTRODUÇÃO}

O presente artigo desenvolve um modelo teórico inédito a respeito do comportamento do vestibulando e de como se dá a alocação do tempo para o estudo. Para isto, baseia-se nas teorias microeconômicas do consumidor e da produção. As hipóteses dessas duas teorias são muito pouco restritivas. Com efeito, supõe-se que o indivíduo, como consumidor, é racional, ou seja, procura escolher uma cesta de consumo que torna a sua satisfação máxima dadas as suas restrições de recursos de tempo, que é variável endógena do modelo, e que ele precisa alcançar um escore mínimo para ser aprovado no vestibular. Supõe-se que esse escore mínimo seja função crescente do excesso de demanda por vagas; como produtor, o indivíduo é eficiente, ou seja, ele é capaz de extrair o máximo de produto dos seus recursos de tempo e financeiros, e com base em suas características pessoais como a idade, o sexo, a escolarização e a habilidade intelectual.

Enquanto o modelo teórico estabelece um arcabouço de comportamento do candidato, sendo, portanto, uma análise ex-ante, pois ocorre antes de o candidato se inscrever no curso para o qual vai prestar o vestibular, o modelo empírico é necessariamente ex-post, ou seja, após o indivíduo ter realizado a prova vestibular. $\mathrm{O}$ modelo teórico retrata a alocação de tempo potencial do indivíduo para o estudo e para o trabalho e outras atividades, como lazer, transporte, sono etc., que são, enfim, as alocações destinadas à produção de $Q$, que é um bem agregado. Assim, a estratégia adotada para verificar se o modelo teórico se conforma aos dados consistirá em observar a correlação estatística entre o tempo que o indivíduo dispõe para a produção do bem agregado, $\mathrm{Q}(\mathrm{tq})$, e o escore mínimo para ser aprovado no curso a que ele se candidata.

Levin e Tsang (1987) desenvolveram um modelo na linha aqui adotada, mas sem chegarem a deduzir a função de produção educacional correspondente, por meio de um processo de maximização da utilidade do consumidor dadas desigualdades nas restrições. Ademais, esses autores não testaram o modelo empiricamente, o que é feito neste trabalho. Além disso, esta é a primeira formalização do comportamento do vestibulando, até onde vai o conhecimento deste autor.

Este artigo estrutura-se da seguinte maneira: além desta introdução, na segunda seção desenvolve-se o modelo teórico e analisam-se algumas de suas implicações; na terceira seção, discute-se sobre a base de dados e as variáveis utilizadas; na quarta seção, desenvolve-se o modelo empírico de uma função de produção educacional a partir do modelo teórico; nas 
quinta e sexta seções discutem-se os resultados empíricos e, por fim, apresentam-se as principais conclusões.

\section{DESENVOLVIMENTO DO MODELO TEÓRICO}

Suponha-se que o indivíduo produza dois bens eficientemente, $A=A(t a, I d, R, X, Z)$, e um bem agregado, $Q=Q(t q)$, ambos funções do tempo de estudo ${ }^{2}$, ta, e do tempo que o indivíduo dedica à produção de $Q$, tq, respectivamente. $\mathrm{A}(\mathrm{ta}, \mathrm{Id}, \mathrm{R}, \mathrm{X}, \mathrm{Z})$ é medido pelo escore que o indivíduo obtém no vestibular. $X$ é um vetor de características do candidato, formado por variáveis binárias demográficas e sociais, tais como sexo, tipo de escola que freqüentou, se pública ou particular etc., Id é a idade do candidato, R é a renda familiar e $Z$ é a habilidade intelectual do candidato (esta última variável não é observável). Quanto à $Q$, este não é observável, mas o fator de sua produção, tq, o é. Além de produzir esses dois bens, esse indivíduo maximiza a sua função utilidade, $\mathrm{U}($. ), quase-côncava. A utilidade é a escala de preferências do indivíduo e, como tal, reflete a estrutura de sua personalidade, psicologia e contexto social em que o indivíduo se insere.

Considerando-se a racionalidade do vestibulando, supõe-se que o seu comportamento possa ser descrito pelo problema de maximização condicionado (1):

$$
\begin{aligned}
& \text { Max U[A(ta, Id , R, X, Z),Q(tq)] } \\
& \text { ta, tq }
\end{aligned}
$$

sujeito às seguintes restrições:

$$
\begin{aligned}
& \mathrm{ta}+\mathrm{tq} \leq \mathrm{T} \\
& \mathrm{A}(\mathrm{D}-\mathrm{S})_{\mathrm{jt}} \leq \mathrm{A}(\mathrm{ta}, \mathrm{Id}, \mathrm{R}, \mathrm{X}, \mathrm{Z})
\end{aligned}
$$

Onde T é o total de horas que o indivíduo dispõe por semana, ta é a quantidade potencial de horas/semana destinada ao estudo, e tq é a quantidade de horas/semana destinada à produção de $Q$. A(D-S $)_{j t}$ é o escore mínimo esperado para ser aprovado em um determinado curso j no vestibular e no ano $t$, e ele é função crescente do excesso de demanda por vagas, $\mathrm{D}-\mathrm{S}$; $\mathrm{D}$ corresponde à demanda agregada pelo curso e $\mathrm{S}$ à oferta de vagas.

2 Entenda-se por tempo de estudo o tempo que o indivíduo dedica ao estudo formal (presença em sala de aula) e o estudo informal (individual ou em grupo, fora da sala de aula). 
$\mathrm{O}$ indivíduo, quando se inscreve em determinado curso no vestibular, forma uma expectativa quanto ao valor de $A(D-S)_{\text {it }}$ com base em seu conjunto de informações (o que inclui informações sobre a concorrência de vestibulares passados). Uma vez que esse escore mínimo depende da demanda por vagas, ele reflete também as condições de mercado de trabalho para determinada profissão, tais como a taxa de desemprego e a renda vitalícia proporcionada pela profissão escolhida. Conforme demonstrado em Avena (2004), há evidências extremamente fortes de que a demanda por vagas do ensino superior é explicada em grande parte pela renda vitalícia proporcionada pela profissão que o candidato escolhe.

Dando prosseguimento à resolução do problema expresso pelo sistema (1), forma-se o Lagrangiano de Kuhn-Tucker dado pela identidade (2):

$$
\begin{array}{r}
\mathrm{L}\left(\mathrm{ta}, \mathrm{tq} ; \theta_{1}, \theta_{2}\right) \equiv \mathrm{U}[\mathrm{A}(\mathrm{ta}, \mathrm{Id}, \mathrm{R}, \mathrm{X}, \mathrm{Z}), \mathrm{Q}(\mathrm{tq})]+\theta_{1}(\mathrm{~T}-\mathrm{ta}-\mathrm{tq})+\ldots \\
\ldots+\theta_{2}[\mathrm{~A}(\mathrm{ta}, \mathrm{Id}, \mathrm{R}, \mathrm{X}, \mathrm{Z})-\mathrm{A}(\mathrm{D}-\mathrm{S})]
\end{array}
$$

Supõe-se que as funções $\mathrm{U}($ ), $\mathrm{A}($ ) e $\mathrm{Q}($ ) têm as seguintes derivadas parciais:

$$
\mathrm{U}_{\mathrm{A}}, \mathrm{U}_{\mathrm{Q}}>0 \text { e } \mathrm{A}_{\mathrm{ta}}, \mathrm{A}_{\mathrm{z}}, \mathrm{A}_{\mathrm{R}} \text { e } \mathrm{Q}_{\mathrm{tq}}>0 \text { e } \mathrm{A}_{\mathrm{Id}}<0
$$

Os sinais dessas derivadas parciais são explicados pelas seguintes razões: quanto maior o consumo de $A$ ou de $Q$, maior o nível de satisfação (utilidade) do indivíduo; este é um pressuposto da teoria do consumidor, segundo o qual o indivíduo prefere mais a menos de um bem; no que diz respeito ao escore no vestibular, $\mathrm{A}$, quanto maior o tempo dedicado ao estudo, ta, quanto maior a habilidade intelectual do indivíduo, $Z$, quanto maior a renda familiar do indivíduo, $\mathrm{R}$, ceteris paribus, maior o seu escore; entretanto, quanto maior (menor) a idade do candidato, Id, menor (maior) o escore do candidato, tudo mais constante. $\mathrm{O}$ efeito da idade sobre o escore se explica porque quanto mais tempo o indivíduo encontra-se afastado dos estudos, menor o estoque de capital humano do candidato, pois o seu estoque de conhecimentos deverá se depreciar.

Soares e Fonseca (1998), em estudo sobre os fatores determinantes do desempenho no Vestibular da UFMG, observaram que quanto mais cedo o candidato conclui o ensino médio, quanto maior a renda per capita e quanto maior o índice de posição social do candidato, maior o índice de aprovação. Esses resultados respaldam alguns dos sinais das derivadas parciais acima. 
Pelas condições de primeira ordem, de (2), e pelas condições de folga de Kuhn-Tucker em (6) e (7):

$$
\begin{aligned}
& (\partial \mathrm{L} / \partial \mathrm{ta})=(\partial \mathrm{U} / \partial \mathrm{A})(\partial \mathrm{A} / \partial \mathrm{ta})-\theta_{1}+\theta_{2}(\partial \mathrm{A} / \partial \mathrm{ta})=0 \\
& (\partial \mathrm{L} / \partial \mathrm{tq})=(\partial \mathrm{U} / \partial \mathrm{Q})(\partial \mathrm{Q} / \partial \mathrm{tq})-\theta_{1}=0 \\
& \left(\partial \mathrm{L} / \partial \theta_{1}\right)=\mathrm{T}-\mathrm{ta}-\mathrm{tq} \geq 0 \text { se } \theta_{1} \geq 0 \text { ou } \mathrm{T}=\mathrm{ta}+\mathrm{tq} \text { se } \theta_{1}>0 \\
& \left(\partial \mathrm{L} / \partial \theta_{2}\right)=\mathrm{A}(\mathrm{ta}, \mathrm{Id}, \mathrm{R}, \mathrm{X}, \mathrm{Z})-\mathrm{A}(\mathrm{D}-\mathrm{S}) \geq 0 \text { se } \theta_{2} \geq 0 \text { ou }
\end{aligned}
$$

$$
\mathrm{A}(\mathrm{ta}, \mathrm{Id}, \mathrm{R}, \mathrm{X}, \mathrm{Z})-\mathrm{A}(\mathrm{D}-\mathrm{S})=0 \text { se } \theta_{2}>0^{3}
$$

Substituindo (5) em (4) e arrumando os termos:

$$
(\partial \mathrm{A} / \partial \mathrm{ta}) /(\partial \mathrm{Q} / \partial \mathrm{tq})=(\partial \mathrm{U} / \partial \mathrm{Q}) /\left(\partial \mathrm{U} / \partial \mathrm{A}+\theta_{2}\right)
$$

Se $\theta_{2}=0$, a segunda restrição é eliminada e o indivíduo maximizaria a sua utilidade no ponto de tangência da curva de tranformação, ( $\partial \mathrm{A} / \partial \mathrm{ta})$ / $(\partial \mathrm{Q} / \partial \mathrm{tq})$, com a curva de utilidade, $(\partial \mathrm{U} / \partial \mathrm{Q}) /(\partial \mathrm{U} / \partial \mathrm{A})$, indicada por $\mathrm{U}_{1}$. Vide gráfico 1. Ou seja:

$$
(\partial \mathrm{A} / \partial \mathrm{ta}) /(\partial \mathrm{Q} / \partial \mathrm{tq})=(\partial \mathrm{U} / \partial \mathrm{Q}) /(\partial \mathrm{U} / \partial \mathrm{A})
$$

Pelo Teorema de Kuhn-Tucker e para simplificar a análise, admitese que $A(t a)-A(D-S)=0$, restringindo-se a $\theta_{2}>0$. Essa restrição implica que a solução obtida será interior, evitando-se assim as soluções de canto. Em conseqüência, A(ta) = A(D-S), ou seja, o estudante estuda o suficiente para obter o escore mínimo esperado do curso de modo a também produzir uma maior quantidade de $Q$. O equilíbrio será dado pela curva de indiferença $U_{2}$ no Gráfico 1.

Graficamente tem-se o seguinte:

3 Teorema de Kuhn-Tucker. 


\section{Gráfico 1}

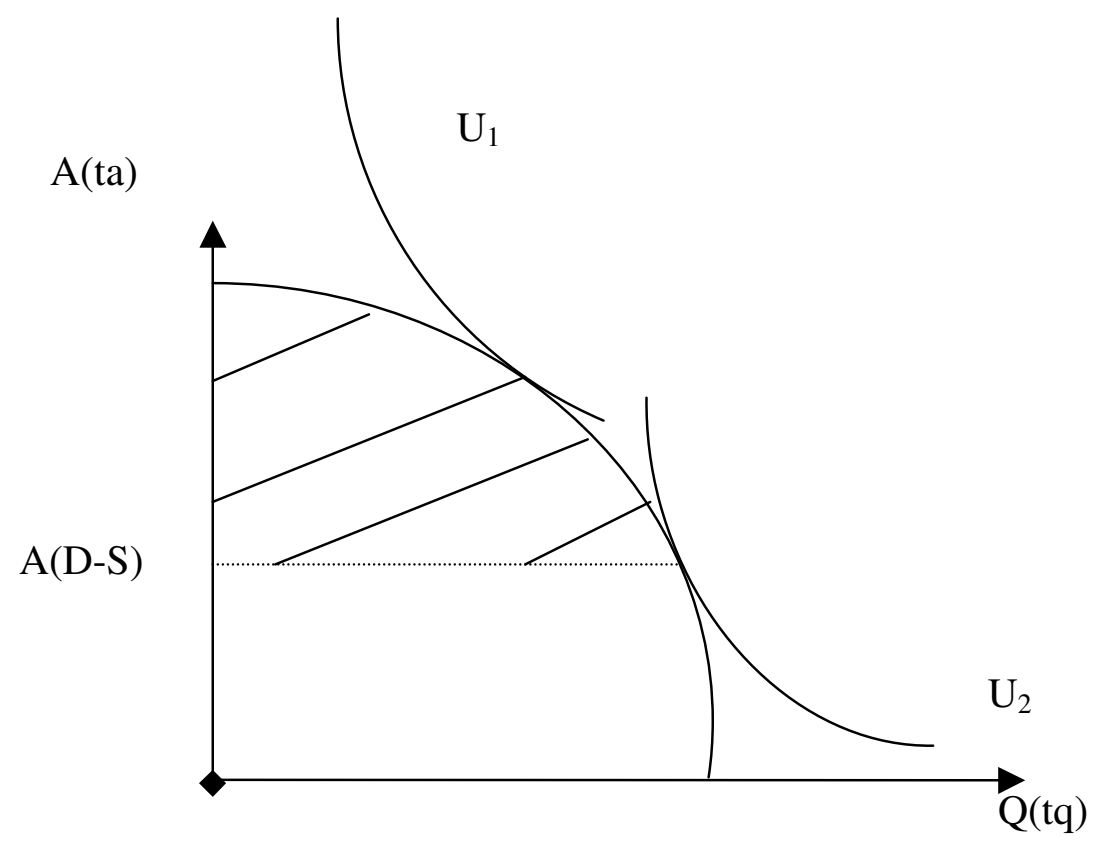

As curvas de transformação e de utilidade se tangenciariam em um ponto mais baixo ou mais alto a depender da concorrência do curso a que o candidato se inscreve. Em outras palavras, ao formar uma expectativa quanto ao valor do escore mínimo para aprovação, o indivíduo estaria dedicando menos tempo ao estudo (se o curso for menos concorrido) e, conseqüentemente, mais tempo para a produção de $\mathrm{Q}(\mathrm{tq})$, para manter a mesma utilidade. No caso de o curso ser mais concorrido, o valor de A(D-S) se elevaria e o candidato dedicaria mais tempo ao estudo e produziria menos de $Q$, o que representaria um custo de oportunidade maior para o candidato em termos de unidades de $\mathrm{Q}$ sacrificadas. De qualquer modo, o indivíduo maximizaria a sua utilidade de acordo com a posição da curva $\mathrm{U}_{2}$ (posição em que ocorreria o equilíbrio), conforme apresentado no Gráfico 1.

Uma implicação desta análise é que o indivíduo que tem muita dificuldade de substituir o tempo destinado à produção de $Q$ para a produção de $\mathrm{A}$, o que é de se esperar principalmente dos alunos que trabalham, e o fazem porque precisam, e/ou não gostam de sacrificar horas de sono e de lazer, tenderão a demandar cursos cujo escore mínimo seja 
mais reduzido, para compatibilizar as suas horas de estudo com a exigência do vestibular. Em outras palavras, levanta-se a hipótese de que ocorre um processo de auto-seleção na escolha do curso antes da inscrição. O indivíduo, nessa decisão, leva em consideração, além da disponibilidade de tempo para estudo, a sua habilidade, $\mathrm{Z}$, a sua capacidade de transformar horas de estudo em escores no vestibular, a sua história familiar e escolar pregressa e a elasticidade da utilidade com respeito ao escore no vestibular, esta última podendo ser interpretada como um maior ou menor pendor e gosto por certa profissão.

Este modelo ressalta a importância das expectativas no ensino que o aluno forma quando se candidata a um concurso ou a um curso. Para fixar as idéias, tome-se uma faculdade ou departamento que seja mais exigente na seleção do que outra(o); sendo o aluno informado disto, seja por meio da estratégia de marketing, seja porque a informação circula entre os indivíduos interessados em determinado curso, esses alunos tenderão a estudar mais de forma a lograrem a classificação, pois o valor de A(D-S) se elevaria.

A(D-S), portanto, pode ser considerada um variável sob controle institucional ou do professor. Com efeito, a faculdade ou departamento poderia estabelecer exogenamente um escore mínimo para aprovação, se assim o desejasse, resultando em alunos selecionados com uma maior base de conhecimentos e, provavelmente, de maior calibre intelectual. Mas se a instituição deixa esse valor para ser estabelecido endogenamente pelo mercado, pela concorrência, o nível intelectual do último aluno selecionado será aquele tal que se preencha a última vaga, o que poderá comprometer a qualidade do curso futuramente, uma vez que, como se sabe, o conhecimento é um processo acumulativo (Bloom, 1976; Todd, Wolping, 2001); quem se apresenta com um menor estoque inicial de conhecimentos provavelmente adquirirá menos conhecimento durante o curso, a menos que realize um esforço suplementar para suprir as suas deficiências.

Existe uma linha de pesquisa em Educação que investiga o papel das expectativas que o professor forma acerca do desempenho e aprendizagem dos seus alunos [conhecida na literatura pelo nome de self fulfilling prophecies (profecias que se auto-realizam)] (Rosenthal, Jacobson, 1992; Jussim, 1989) que advoga que o professor deve estabelecer expectativas elevadas sobre o aprendizado do aluno, pois o aluno se esforçará mais e acabará por satisfazer as expectativas do professor. Pessoalmente, na minha experiência didática como professor de ensino superior, dou um certo crédito a esta hipótese ${ }^{4}$, mas reconheço, também,

4 Existe um Centro de Pesquisas na Universidade Harvard, E.U.A. que se dedica justamente a esta linha de pesquisas. 
que o aluno que não dispõe de tempo suficiente para estudar ou que não gosta de estudar pode desistir do curso ou ter um rendimento sofrível ${ }^{5}$. Isto fica evidenciado pela equação (27).

Resolvendo-se o sistema (4)-(7) para $\theta_{2}$,

$$
\theta_{2}=[(\partial \mathrm{U} / \partial \mathrm{Q})(\partial \mathrm{Q} / \partial \mathrm{tq})-(\partial \mathrm{U} / \partial \mathrm{A}) \cdot(\partial \mathrm{A} / \partial \mathrm{ta})] /(\partial \mathrm{A} / \partial \mathrm{ta})
$$

$\mathrm{O}$ valor de $\theta_{2}$ depende da utilidade que o indivíduo obtém do consumo de $\mathrm{Q}$ e de $\mathrm{A}$, mas depende também das produtividades marginais do tempo dedicado à produção de $\mathrm{Q}$ e de $\mathrm{A}, \partial \mathrm{Q} / \partial \mathrm{tq}$ e $\partial \mathrm{A} / \partial \mathrm{ta}$, respectivamente.

Assim, o indivíduo que prefere estudar mais, porque tem uma expectativa mais elevada do valor de $A(D-S)$, ou porque tem maior prazer nessa atividade comparativamente à utilidade que ele obtém em fazer outras coisas, Q, dedicará mais tempo ao estudo; como conseqüência, a produtividade marginal do tempo dedicado ao estudo se reduz e a produtividade marginal do tempo dedicado à produção de $\mathrm{Q}$ se eleva, de modo que o indivíduo ainda assim maximize a sua utilidade total, ou seja, $\theta_{2}>0$.

\subsection{Implicações do Modelo Teórico}

Suponha-se a função de produção educacional de A definida porø:

$$
\mathrm{A}(\mathrm{ta}, \mathrm{A}(\mathrm{D}-\mathrm{S}), \mathrm{Id}, \mathrm{R}, \mathrm{X}, \mathrm{Z})=\mathrm{C} . \operatorname{ta}^{\varphi} . \mathrm{f}[\mathrm{A}(\mathrm{D}-\mathrm{S}), \mathrm{Id}, \mathrm{R}, \mathrm{X}, \mathrm{Z}]
$$

Onde C é o coeficiente técnico de produção do escore A e $\varphi, 0<\varphi<$ 1 , é a elasticidade-tempo de estudo com respeito ao escore no vestibular. Esta pode ser interpretada como a habilidade do indivíduo em transformar horas de estudo em escore no vestibular. Quanto maior $\varphi$, maior o escore no vestibular, tudo o mais constante.

$\mathrm{O}$ indivíduo de maior habilidade intelectual ( $\mathrm{Z}$ mais elevado), com curva de indiferença $U_{1}$ (Vide gráfico 2 ), e/ ou que tem maior capacidade de transformar horas de estudo em escore no vestibular ( $\varphi$ mais elevado), produz um escore mais elevado com a mesma quantidade de horas de estudo, ta, permitindo-lhe alcançar o escore mínimo esperado, A(D-S), com menos estudo e, assim, consegue produzir uma quantidade maior de $Q$, ou

5 Em futuro trabalho pretende-se investigar a importância do tempo sobre os escores do aluno graduando e sobre a sua probabilidade de conclusão do curso superior.

6 Esta especificação justifica-se por ter sido testada previamente. Entretanto, não é tão completa quanto a da equação (27), razão pela qual se deduzirá esta última. 
seja, ele sacrifica menos o lazer, o sono ou o trabalho. Isto lhe proporciona um nível de satisfação mais elevado, como se pode observar da curva de indiferença $U_{1}$ à direita da curva de indiferença do indivíduo menos hábil, $\mathrm{U}_{2}$, ainda que ambos estejam maximizando as suas utilidades. Supondo-se que a habilidade intelectual inata seja uma variável de distribuição aproximadamente normal e que independa da classe social, uma eventual desigualdade escolar ou de renda futura dela decorrente poderia ser desculpável. O mesmo, entretanto, não se pode dizer sobre o efeito da renda familiar.

O efeito da renda familiar sobre o desempenho no vestibular pode decorrer de que há uma correlação forte entre nível educacional e renda (Avena, 2000) e de que pais com maior nível educacional valorizam mais a educação e transferem a importância da educação para os filhos. A renda familiar mais elevada permite financiar a educação do filho, possibilitando a freqüência às melhores escolas, $\mathrm{o}$ acesso a recursos didáticos e à cultura em geral. Segundo Souza (1979), um aspecto da renda familiar mais elevada é que a família atribui uma importância maior à educação.

Além disso, há evidências recentes na literatura que reforçam a tese sobre a transmissão intergeracional da posição econômica do indivíduo, sendo a renda e a riqueza familiares fortes determinantes do sucesso econômico da geração seguinte, mesmo nos E.U.A., considerados por muitos autores como a terra da oportunidade segundo algumas medidas (Bowles, Gintis, 2002).

Assim, os candidatos de famílias de maior poder aquisitivo podem participar de cursos de maior concorrência, pois a renda familiar mais elevada, além dos aspectos mencionados acima, também permite aos candidatos disporem de um tempo maior para o estudo do que os candidatos de famílias mais pobres7 .

A combinação do modelo de demanda agregada pelos cursos superiores (Avena, 2004) com o modelo de comportamento do vestibulando desenvolvido neste artigo permite o seguinte tipo de análise. Suponha-se o caso de uma determinada profissão cuja demanda no mercado de trabalho se eleva; ceteris paribus, o salário nessa profissão aumenta e, conseqüentemente, mais candidatos se sentirão estimulados a cursarem essa profissão na Universidade. Acontece que, como a quantidade demandada por vagas se eleva mais rapidamente do que a oferta, dá-se um excesso de demanda por vagas nessa profissão; a oferta de vagas nas instituições públicas tem se mostrada bastante inelástica nos últimos decênios (MEC/Inep, 2004). Como corolário, a expectativa quanto

7 Em Tese de Doutorado pretende-se incluir o custo de oportunidade do aluno para estudar e a sua renda vitalícia esperada conforme calculados em Avena (2004). 
ao valor mínimo para ser aprovado no vestibular, A(D-S), se eleva, resultando em candidatos a essas vagas, em sua maioria, provenientes de famílias mais abastadas. Com isto fecha-se o ciclo: a renda de trabalho por determinada profissão se eleva no mercado de trabalho e quem irá se apropriar dessa renda serão indivíduos que já dispõem de um padrão de vida familiar elevado, perpetuando-se a baixa mobilidade social e alta desigualdade de renda.

Uma maneira de se minimizar o efeito do aumento de salário em determinada profissão sobre a elevação do escore mínimo esperado é por meio da cobrança de mensalidade. Com efeito, segundo cálculos apresentados em Avena (2004), a cada 1\% de aumento do custo de oportunidade do estudante, a quantidade demandada se reduz de $0,18 \%$ a $0,25 \%$, a depender da amostra.

Observe-se do Gráfico 2 como opera a seletividade social do vestibular. À medida que $\mathrm{A}(\mathrm{D}-\mathrm{S})$ se eleva, o indivíduo é compelido a estudar mais e a produzir menos de $Q$, elevando-se o seu custo de oportunidade de estudar; uma vez que se torna mais difícil para o candidato pobre suportar custos mais elevados do que para o candidato rico, será este último que se encaminhará para os cursos mais concorridos.

\section{Gráfico 2}

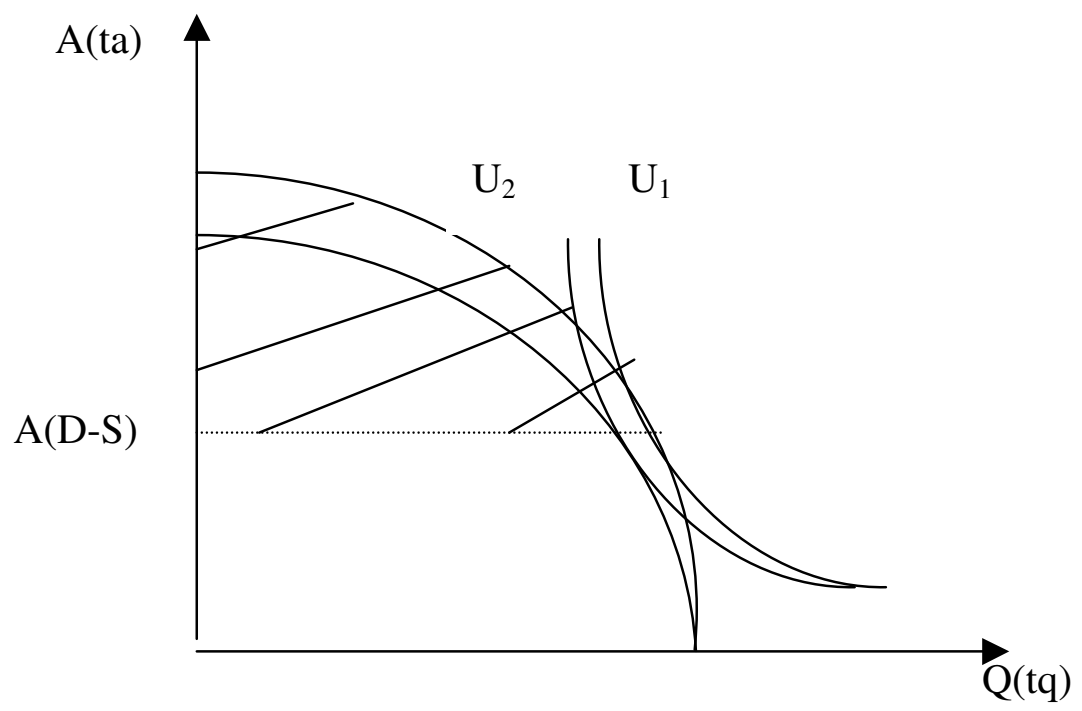


Os sinais das derivadas parciais em (3) e o modelo empírico da equação (27) permitem outras análises, que serão realizadas com base no Gráfico 3:

\section{Gráfico 3}

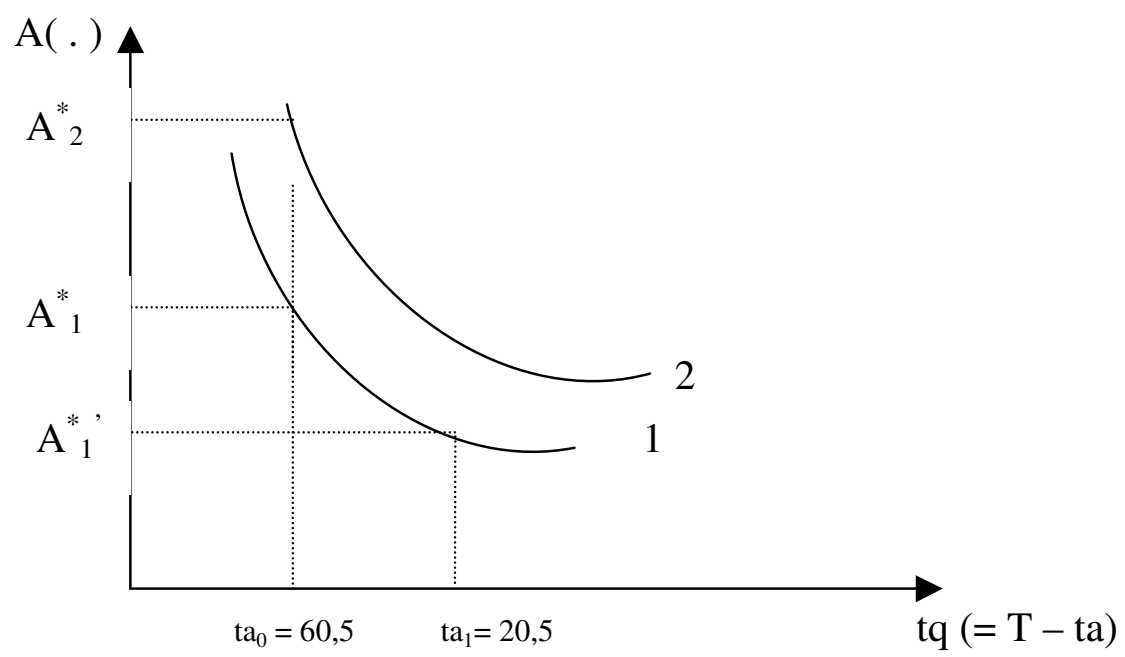

No eixo horizontal (Gráfico 3), quanto mais tempo o indivíduo destina à produção de $\mathrm{Q}$ (tq aumenta), menor a disponibilidade de tempo para estudo (ta diminui). Assim, ao longo de uma mesma curva 1, por exemplo, os candidatos que trabalham menos $\left(\operatorname{ta}_{0}=60,5 \mathrm{~h}\right.$.), têm escores mais elevados, $A^{*}{ }_{1}$, enquanto os que trabalham mais $\left(\operatorname{ta}_{1}=20,5 \mathrm{~h}\right.$.), têm escores mais reduzidos, $\mathrm{A}_{1}^{*}$.

Outra fonte de variabilidade é o escore mínimo esperado. Enquanto a curva 1 representa um curso com escore mínimo esperado mais reduzido, a curva 2 representa um curso com escore mínimo mais elevado. Para cada nível de ta, diga-se, 60,5 horas, o candidato poderá almejar um curso mais concorrido (curva 2), que corresponde a um escore mais elevado, $\mathrm{A}_{2}^{*}$, se ele é intelectualmente mais hábil, se ele teve acesso a uma educação de melhor qualidade, é de família mais rica, que lhe tenha proporcionado um ambiente culturalmente mais rico, se ele tem uma maior capacidade de transformar as horas de estudo em escores e/ou ele gosta de estudar mais etc. Caso contrário, ele tenderá a se encaminhar para os cursos menos concorridos (curva 1), em que o escore é menor, $\mathrm{A}^{*}{ }_{1}$. 


\section{OS DADOS E AS VARIÁVEIS}

Foram utilizadas as bases de dados dos candidatos inscritos no vestibular dos anos de 1993, 1994 e 1995. Apesar de dispor de dados também dos anos de 1997, 1998 e 2001, estes não foram incluídos nesta análise, feita em corte transversal, pois a sistemática de cômputo dos escores foi alterada e a sua utilização distorceria os resultados. Por exemplo, até o ano de 1995 (inclusive), os escores são medidos na ordem de cem milhares e, a partir de 1997, eles são medidos em unidades de mil.

Os escores totais utilizados neste trabalho resultam da soma dos escores parciais obtidos na $1^{\mathrm{a}}$ e na $2^{\mathrm{a}}$ etapas do processo de seleção; antes, porém, esses escores parciais haviam sido previamente transformados em escores z padrão pelo setor competente da Universidade, de acordo com a fórmula (12). O escore mínimo para ser aprovado foi obtido observando-se, para cada curso j e ano t, o escore total do último aluno aprovado.

$$
\mathrm{A}(\text {. })_{\mathrm{ijt}}=\left(\mathrm{Y}_{\mathrm{ijt}}-\mathrm{Y}_{\mathrm{jt}}\right) / \mathrm{S}_{\mathrm{jt}}
$$

Onde

$\mathrm{A}(\text {. })_{\mathrm{ijt}}$ é o escore total obtido pelo candidato i, no curso j e ano t.

$\mathrm{Y}_{\mathrm{j} \mathrm{t}}$ é o valor médio amostral dos escores globais no curso j e ano $\mathrm{t}, \mathrm{e}$ $\mathrm{S}_{\mathrm{j} t}$ é o desvio-padrão amostral dos escores globais no curso j e ano t.

As três bases em conjunto totalizam 87.989 casos; há determinados casos cujas observações se apresentam ausentes, sendo automaticamente excluídas da análise, realizada no pacote estatístico SPSS.

As variáveis da Tabela 1 (Anexo) assinaladas com um asterisco $\left(^{*}\right)$ são variáveis binárias que assumem o valor 1 em caso afirmativo e valor 0 em caso contrário. A variável do banco de dados "Motivos que o levaram a escolher o curso" foi transformada em três variáveis dicotômicas, englobando todas as respostas possíveis do questionário. Essas três variáveis binárias são descritas a seguir.

A primeira variável binária, criada denominada "Se a escolha do curso foi baseada em interesse pessoal (econômico ou status social) " engloba as seguintes categorias: 1) o curso oferece vantagem econômica, 2) o curso facilita a obtenção de emprego; 3) o curso é fácil, o que permite concluí-lo rápido; 4) o curso permite conciliar com outros interesses; 5) permite conciliar o curso (as aulas) com o trabalho; e 6) o curso dá prestígio social. Em qualquer desses casos a variável assume o valor um; caso contrário, assume o valor zero. 
A segunda variável binária é "Se acha que a escolha do curso é adequada às aptidões"; quando o candidato responde sim, a variável assume o valor um e zero em caso contrário. É um total de 64.399 (73,2\%) de respostas positivas e a variável mostrou-se estatisticamente significativa na regressão da Tabela 1, nos Anexos.

A terceira variável é omitida para se evitar perfeita colinearidade e ela engloba as seguintes categorias: 1) o curso é útil para o desenvolvimento do País; 2) se o curso permite conhecer pessoas interessantes; 3) se a concorrência do curso no vestibular é pequena; e 4) outros motivos.

As demais variáveis da Tabela 1 são auto-explicativas ou já foram definidas anteriormente no texto. Ressalte-se, entretanto, que a variável ta não corresponde ao tempo que o aluno destina ao estudo efetivamente, porque esse tempo não está disponível, mas ele retrata a disponibilidade de tempo que o indivíduo tem para estudar, seja estudo formal, na escola de ensino médio ou cursinho pré-vestibular, seja o estudo informal, individual ou coletivo; neste sentido, deve ser encarada como um tempo potencialmente utilizado para estudo. Ela foi obtida do seguinte modo: ta $=\mathrm{T}-\mathrm{tq}$, onde $\mathrm{T}=168$ horas/semana que é a dotação de qualquer indivíduo; tq, por sua vez, foi obtida segundo o Quadro 1:

\section{Quadro 1: Composição do tempo tq}

\begin{tabular}{|l|c|}
\hline Sono & 56 \\
\hline Lazer & 20 \\
\hline Higiene pessoal & 7 \\
\hline Transporte & 14 \\
\hline Alimentação & 10.5 \\
\hline Horas de trabalho & h.t. \\
\hline
\end{tabular}

Fonte: Estimativas do autor.

Dolton et al. (2003) estimou, com base em amostra de estudantes universitários australianos, as seguintes alocações diárias de tempo: 5 horas e $36 \mathrm{~min}$ para lazer, $7 \mathrm{~h}$. e $45 \mathrm{~min}$. para o sono, $1 \mathrm{~h}$ e $50 \mathrm{~min}$. para transporte, 4 horas para estudo formal e $3 \mathrm{~h}$. e $45 \mathrm{~min}$. para estudo próprio.

Horas de trabalho, h.t., é uma variável intervalar com 87.271 observações válidas cuja distribuição de probabilidade, f(h.t.), é como segue em (13): 


$$
f(\text { h.t. })=\left\{\begin{array}{l}
0,622 \text {, se } h . t \leq 0 \text { horas } \\
0,179, \text { se } 0<\text { h.t } \leq 20 \text { horas } \\
0,073 \text {, se } 20<\text { h.t } \leq 30 \text { horas } \\
0,118 \text {, se } 30<\text { h.t } \leq 40 \text { horas } \\
0, \text { se h.t. }>40 \text { horas }
\end{array}\right.
$$

Da distribuição (13), verifica-se que $62,2 \%$ dos candidatos inscritos não trabalham. Tomou-se o ponto h.t. $=20$ para representar a $2^{\mathrm{a}}$ classe; 25 horas para a $3^{\mathrm{a}}$ classe e 40 horas para a $4^{\mathrm{a}}$ classe, pois, em verdade, a $4^{\mathrm{a}}$ classe dispõe da informação no ponto h.t. $=40$ horas. Deste modo, tq assumiu valores no intervalo $107,5 \leq \mathrm{tq} \leq 147,5$ e, conseqüentemente, ta está definido no intervalo, 20,5 $\leq$ ta $\leq 60,5$.

As variáveis "Se o curso escolhido é da área L" (onde $L=1,2,3$ e 4) são obtidas do seguinte modo: a área 1 é a de exatas, formada por Arquitetura, Engenharias, Ciência da Computação, Geofísica, Matemática, Estatística etc. A área 2 são os cursos de ciências médicas e biológicas: Farmácia, Enfermagem, Nutrição, Odontologia etc. A área 3, por sua vez, corresponde aos cursos de ciências sociais e humanas: Administração, Ciências Econômicas e Contábeis, Educação Física, Direito, Jornalismo, Psicologia, Pedagogia etc. A área 4 é formada pelos cursos de Letras e a área 5, são os cursos de Artes Plásticas, Teatro, Desenho, Dança, Música etc.

As variáveis de referência ou base nas variáveis binárias são: "Se é residente no interior ou em outro estado", "Se a casa onde mora é cedida", "Se o curso é da área 5", "Se o curso é útil para o desenvolvimento do País", "Se a concorrência é pequena ou se permite conhecer pessoas interessantes"; "Se proveniente de magistério ou supletivo", "Se optou pela língua francesa ou espanhola"; a variável base da variável "Se procura uma melhora na situação profissional atual" é: "Se o candidato procura aumento de conhecimento, formação profissional, formação teórica, formar consciência crítica ou outros". Outras variáveis-base são: "Se mora em pensionato, república, residência universitária ou sozinho"; "Se quem sustenta é pai, mãe, cônjuge, parente ou irmão", "Se o nível de instrução do pai é superior incompleto ou inferior" e "Se o nível de instrução da mãe é superior incompleto ou inferior". 


\section{DESENVOLVIMENTO DO MODELO EMPÍRICO}

Nesta seção desenvolve-se o modelo empírico de uma função de produção educacional a partir de um processo de otimização da utilidade dadas as restrições de tempo do indivíduo e de que ele precisa alcançar um escore no vestibular que permita que ele seja aprovado. Para isto, parte-se da tautologia dada por (14):

$(\partial \mathrm{A} / \partial \mathrm{ta}) /(\partial \mathrm{Q} / \partial \mathrm{tq}) \equiv(\partial \mathrm{U} / \partial \mathrm{Q}) \cdot(\partial \mathrm{A} / \partial \mathrm{ta}) /(\partial \mathrm{U} / \partial \mathrm{Q}) \cdot(\partial \mathrm{Q} / \partial \mathrm{tq})$

Suponha-se uma função de utilidade Cobb-Douglas, conforme definido em (15):

$$
\mathrm{U}[\mathrm{A}(\mathrm{ta}), \mathrm{Q}(\mathrm{tq})]=[\mathrm{A}(\mathrm{ta})]^{\alpha} \cdot[\mathrm{Q}(\mathrm{tq})]^{1-\alpha}
$$

Onde $0<a<1$ é a elasticidade da utilidade com respeito ao bem escore no vestibular, $\mathrm{A}($. . ).

Calculando-se ( $\partial \mathrm{U} / \partial \mathrm{Q})$ e substituindo-se esse resultado em (14) e re-arrumando-se:

$$
(\partial \mathrm{A} / \partial \mathrm{ta}) /(\partial \mathrm{Q} / \partial \mathrm{tq})=[(1-\mathrm{a}) \cdot \mathrm{U} / \mathrm{Q}(\mathrm{tq})] /[(\partial \mathrm{U} / \partial \mathrm{Q}) \cdot(\partial \mathrm{Q} / \partial \mathrm{tq}) /(\partial \mathrm{A} / \partial \mathrm{ta})]
$$

Uma vez que a inclinação de dada curva de utilidade U é dada por:

$$
\mathrm{dta} / \mathrm{dtq}=-(\partial \mathrm{U} / \partial \mathrm{Q})(\partial \mathrm{Q} / \partial \mathrm{tq}) /(\partial \mathrm{U} / \partial \mathrm{A}) \cdot(\partial \mathrm{A} / \partial \mathrm{ta})
$$

Substituindo-se (17) em (16):

$(\partial \mathrm{A} / \partial \mathrm{ta}) /(\partial \mathrm{Q} / \partial \mathrm{tq})=[(1-\mathrm{a}) . \mathrm{U} / \mathrm{Q}(\mathrm{tq})] /[(\partial \mathrm{U} / \partial \mathrm{A}) \cdot(-\mathrm{dta} / \mathrm{dtq})]$

Lembrando que,

$$
(\partial \mathrm{U} / \partial \mathrm{A})=\mathrm{a} \cdot \mathrm{U} / \mathrm{A}(\mathrm{ta})
$$

Substituindo-se (19) em (18) e simplificando:

$(\partial \mathrm{A} / \partial \mathrm{ta}) /(\partial \mathrm{Q} / \partial \mathrm{tq})=[(1-\mathrm{\alpha}) / \mathrm{a}] .[\mathrm{A}(\mathrm{ta}) / \mathrm{Q}(\mathrm{tq})] \cdot(-\mathrm{dtq} / \mathrm{dta})$ 
Re-escrevendo-se (20) e resolvendo, resulta:

$$
\operatorname{Ln} A(t a)=[(1-a) / a]) \cdot(-d t q / d t a) \cdot \ln Q(t q)
$$

Onde, dtq/dta é a taxa marginal de substituição entre os insumos, tempo alocado à produção de $\mathrm{Q}$, tq, e o tempo alocado ao estudo para a produção de $\mathrm{A}$, ta.

A equação (21) revela que quanto mais tempo se dedica à produção de $\mathrm{Q}(\mathrm{tq})$, cai a produção de $\mathrm{A}(\mathrm{ta})$, pois, como se verá, $\mathrm{dtq} / \mathrm{dta}>0$.

Com efeito, suponha-se a seguinte função de produção do bem agregado, $\mathrm{Q}(\mathrm{tq})$ :

$$
\mathrm{Q}(\mathrm{tq})=\mathrm{B} \cdot \mathrm{tq}^{\varepsilon}
$$

Onde B é o coeficiente técnico na produção de $Q$ e é suposto igual a um $^{8}$, e $0<\varepsilon<1$ para que a função de produção de $Q($ tq) apresente rendimentos físicos marginais decrescentes com respeito ao tempo dedicado à sua produção. $\varepsilon$ é a capacidade do indivíduo de transformar horas alocadas à produção de $\mathrm{Q}$, em $\mathrm{Q}$.

Dando prosseguimento à dedução do modelo empírico, substituemse as derivadas parciais em (10), obtém-se:

$$
\begin{array}{r}
\theta_{2}=\mathrm{U} \cdot \mathrm{ta} \cdot[(1-\alpha) \cdot \varepsilon-\alpha \varphi] / \varphi \cdot \mathrm{A}(\mathrm{ta})=[(\partial \mathrm{U} / \partial \mathrm{A}) \cdot \operatorname{ta} / \alpha \varphi] \cdot[(1-\alpha) \cdot \varepsilon / \mathrm{tq}-(\alpha \varphi) / \mathrm{ta}]= \\
=(\partial \mathrm{U} / \partial \mathrm{A}) \cdot[(1-\alpha) \cdot \varepsilon \cdot \mathrm{ta} /(\alpha \varphi \mathrm{tq})-1]
\end{array}
$$

Ou seja, como $(\partial \mathrm{U} / \partial \mathrm{A})>0$,

$\theta_{2}>0$ implica que (1- a). $\varepsilon /$ tq $>$ a $\varphi /$ ta $\leftrightarrow$ ta $>$ [a. $\left.\varphi / \varepsilon(1-\alpha)\right]$ tq

Existe uma constante positiva $\mathrm{h}$ (referente a um certo número de horas) tal que, a partir da inequação (24):

$$
\text { ta }=[\alpha \cdot \varphi / \varepsilon(1-\alpha)] \cdot t q+h
$$

8 B=1 é condição para que exista solução na determinação dos parâmetros do coeficiente de $\ln (\mathrm{tq})$, na equação (27). Uma vez que $\operatorname{Ln} \mathrm{Q}(\mathrm{tq})>0$, pois não faz sentido dispender tempo com algo cuja produção seja não-positiva, tem-se de (22) que $\ln B+\varepsilon \cdot \ln (\mathrm{tq})>0$, o que equivale a $\varepsilon>-\operatorname{LnB} / \operatorname{Ln}(\mathrm{tq})$. Sucede que à medida que $\varepsilon$ cresce, $|-\ln B|$ também cresce, $\mathrm{o}$ que implica que não haveria solução que satisfizesse $0<\varepsilon<1$. Daí se impõe que $B=1$. 


\section{Conseqüentemente,}

$$
\mathrm{dtq} / \mathrm{dta}=\varepsilon(1-\alpha) / \alpha \cdot \varphi>0
$$

A equação (26) revela que o indivíduo está disposto a substituir as horas de estudo por horas na produção de $Q$, quanto maior for $\varepsilon$, a sua capacidade de transformar tq (horas alocadas à produção de $Q$ ) em $Q$, e quanto maior for (1- $\alpha)$, a sua preferência por produzir $Q$ a ter que estudar para produzir A. Por outro lado, ele resiste a substituir o tempo destinado à produção de A quanto mais ele goste de estudar, a, e maior for a sua capacidade de transformar horas destinadas à produção de $\mathrm{A}, \varphi$.

Substituindo-se (22) (esta, após se tomar o logaritmo) e (26) em (21) e acrescentando-se as variáveis exógenas $\mathrm{A}(\mathrm{D}-\mathrm{S}), \mathrm{Id}, \mathrm{R}$ e $\mathrm{X}$ chega-se à equação (27) cujas estimativas encontram-se nas Tabelas 1 e 2 em Anexo:

$$
\begin{aligned}
\operatorname{LnA}(\operatorname{ta}, \mathrm{A}(\mathrm{D}-\mathrm{S}), \mathrm{Id}, \mathrm{R}, \mathrm{X})=(-1 / \varphi)[(1-\alpha) \cdot \varepsilon / \mathrm{\alpha}]^{2} \ln (\mathrm{tq})+\ldots \\
\ldots+\mathrm{f}[\mathrm{A}(\mathrm{D}-\mathrm{S}), \mathrm{Id}, \mathrm{R}]+\Sigma_{\mathrm{j}} \delta_{\mathrm{j}} \cdot \mathrm{X}_{\mathrm{j}}+\mathrm{v}^{9}
\end{aligned}
$$

A equação (27) é uma função de produção educacional que relaciona o logaritmo neperiano do escore do curso a que se candidatou no vestibular com o logaritmo do tempo dedicado às outras atividades que não o estudo, tq, e, $X$, um conjunto de variáveis binárias relativas às características do candidato, tais como sexo, escolaridade dos pais, do próprio vestibulando etc. Além disso, espera-se que quanto menor (maior) a idade do candidato maior (menor) seja o escore no vestibular, pois quanto mais velho o candidato, mais tempo ele deve estar afastado dos estudos, acarretando uma depreciação de seu estoque de capital humano, e quanto maiores o escore mínimo para ser aprovado e a renda familiar, maior o seu escore no vestibular, ceteris paribus; ademais, quanto maior a habilidade $\varepsilon$ do indivíduo em transformar as horas tq na produção de $Q$, menor o escore no vestibular, quanto maior a sua habilidade $\varphi$ em transformar as horas de estudo em escore e quanto maior a preferência a do indivíduo pelo estudo, maior o escore no vestibular, como seria de se esperar.

9 Esta última parcela é o termo estocástico, suposto normalmente distribuído com média $\mu$ e variância $\sigma^{2}$. 


\section{RESULTADOS DOS MODELOS EMPÍRICOS}

Faz-se a hipótese de que a expectativa que o candidato i forma sobre o escore mínimo para ser aprovado no curso $\mathrm{j}$ pretendido no ano $\mathrm{t}$ se realize, ou seja, $\mathrm{E}\left[\mathrm{A}(\mathrm{D}-\mathrm{S})_{\mathrm{ijt}} \mid \mathrm{I}\right]=\mathrm{A}(\mathrm{D}-\mathrm{S})_{\mathrm{jt}}$, onde I é o conjunto de informações do candidato ${ }^{10}$. Com base nisto, estimou-se a equação (27) com Ln $\left.\mathrm{A}\left[\mathrm{A}(\mathrm{D}-\mathrm{S})_{\mathrm{j} t}, \mathrm{tq}_{\mathrm{i}}, \mathrm{Id}_{\mathrm{i}}, \mathrm{R}_{\mathrm{i}}, \mathrm{X}_{\mathrm{i}}\right)\right]$ como variável dependente para cada candidato da amostra, cujo resultado se encontra na Tabela 1. Na estimação econométrica da Tabela 2 (Anexo), controlou-se para outras variáveis além do excesso de demanda, inclusive para se verificar qual o efeito que a variável tq teria sobre a decisão do candidato escolher um curso mais ou menos concorrido.

Os resultados da Tabela 2 evidenciam que ocorre um processo de auto-seleção no vestibular. Como se pode observar do coeficiente de $\ln (\mathrm{tq})$, $-0,00813$, com estatística $\mathrm{t}$ de -3.468 , quanto maior o tempo alocado à produção de $Q$, menor o escore mínimo esperado do curso a que o candidato se inscreve. Assim, o candidato que trabalha e apresenta um tq mais elevado, estará preferindo um curso menos concorrido, de modo a ampliar as suas chances de ingressar na Universidade. Ou seja, estaria ocorrendo um processo de auto-seleção do candidato mais pobre (aquele com menor disponibilidade de tempo para o estudo) ao excluir-se dos cursos mais concorridos.

Uma vez que a demanda agregada pelo curso é maior quanto maior a renda vitalícia proporcionada pela profissão escolhida, estaria ocorrendo a perpetuação das condições socioeconômicas do indivíduo, e a UFBA estaria se configurando como uma instituição que reproduz a estrutura de classes sociais ${ }^{11}$.

Observe-se na Tabela 2 que o modelo apresentou um coeficiente de determinação múltiplo muito elevado, chegando a alcançar $78,4 \%$, e as variáveis utilizadas apresentaram-se muito significativas estatisticamente, tanto individualmente quanto em seu conjunto, conforme atestam as estatísticas t e F, respectivamente. A amostra utilizada de 80.443 candidatos também é de tamanho considerável.

10 Se eventualmente essa formação de expectativa for considerada muito forte, poder-se-ia

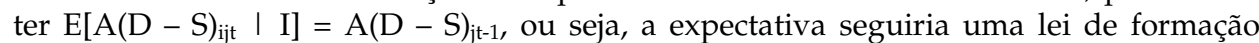
estática. Eventualmente, esta formação produz resultados empíricos melhores do ponto de vista da qualidade do ajuste, mas o custo a pagar é a perda de um ano de observações. Pretende-se testar essa possibilidade em um outro trabalho.

11 As evidências apontam no sentido de ser essa a característica das universidades públicas em geral conforme ampla literatura que trata da seletividade social do vestibular e de estudos empíricos referenciados neste artigo. 
Segundo a Tabela 2, o excedente de demanda, D-S, especificado na forma logarítmica, apresentou um alto poder de explicação do escore mínimo esperado, sendo esta variável, isoladamente, responsável por grande parte do poder de explicação do modelo; entretanto, resolveu-se incluir as demais variáveis pois, a priori, acreditou-se que as mesmas influenciassem na formação da expectativa do candidato, o que acabou se confirmando; este resultado atesta o acerto da hipótese no modelo teórico de que o excesso de demanda explicasse o escore mínimo para aprovação, demonstrando a excelente capacidade explicativa e preditiva do mesmo. Ou seja, esse resultado indica que os alunos formam as suas expectativas de escore mínimo para aprovação com base na concorrência do curso, que é uma informação amplamente divulgada e acessível a qualquer candidato que pretende prestar o concurso vestibular. A estatística t dessa variável foi de 463,58 .

A variável "renda familiar" também se mostrou muito significativa estatisticamente $(t=11,44)$ e positiva. Isto demonstra que a renda familiar é uma variável que influencia na decisão do candidato em escolher um curso mais ou menos concorrido: aqueles de renda familiar maior (menor) tenderiam a escolher um curso mais (menos) concorrido.

Uma variável que pode estar retratando a qualidade da escola é se o ensino médio do aluno foi em escola pública ou na maior parte do tempo nesse tipo de escola; neste caso, o escore esperado do candidato é inferior em $0,155 \%$, em média, se comparado ao candidato da escola particular; curiosamente, se a escola de ensino médio foi na capital o candidato obtém um escore $0,162 \%$ inferior, em média, a quem fez o curso médio no interior ou outro estado.

O coeficiente da idade mostrou-se negativo e altamente significativo, revelando que os candidatos mais velhos preferem cursos menos concorridos por, provavelmente, se encontrarem há mais tempo afastados dos estudos. A escolaridade "superior completo" dos pais, no entanto, encoraja o candidato a arriscar um curso mais concorrido.

$\mathrm{O}$ candidato que fez o curso colegial, técnico ou cursinho prévestibular tende a almejar uma carreira mais competitiva. $\mathrm{O}$ mesmo ocorrendo com o candidato do sexo masculino. Uma variável que poderia se aproximar da habilidade do candidato é se ele foi aprovado e foi matriculado no $2^{\circ}$ semestre do ano em que foi aprovado. Nesse caso, o seu escore se reduz se comparado com quem foi aprovado e matriculado no $1^{\circ}$ semestre.

As variáveis relativas às áreas dos cursos (áreas 1, 2, 3, 4 e 5) revelaram-se altamente significativas, mas, estranhamente, os seus coeficientes foram negativos. Por fim, a variável "tempo" serviu para 
controlar a redução das expectativas dos candidatos quanto ao escore mínimo ao longo dos anos de 1993 a 1995.

Objetivando estimar os coeficientes da função de produção educacional (27), desta vez com o escore total efetivamente obtido pelo aluno, rodou-se uma nova regressão cujos resultados são apresentados nas Tabelas 1 e 3 .

A Tabela 1 mostra que a variável "ln" (escore mínimo) impacta positivamente o escore e é altamente significativa estatisticamente; esta variável é a expectativa que o estudante forma do valor do escore mínimo que ele precisa alcançar para ser aprovado. Consoante o modelo teórico, é com base nessa expectativa que ele aloca as suas horas para o estudo ${ }^{12}$. Conforme apresentado na Tabela 2 e comentado acima, o candidato forma essa expectativa a partir do excesso de demanda pelo curso; assim, se o excesso de demanda é maior (menor), os candidatos que dispõem de mais (menos) tempo procuram estudar mais (menos) para serem aprovados. Com efeito, a cada 1\% de aumento (redução) do escore mínimo ocorre um aumento (redução) de $0,47 \%$ do escore efetivo.

A idade também se mostrou altamente significativa e, conforme o esperado, é relacionada negativamente com o escore. Esta variável capta a depreciação do estoque de capital humano pois, quanto mais velho se é, mais difícil se torna aprender uma tarefa ou até mesmo se desaprende o que se sabia, tudo o mais constante.

A renda familiar, como esperado, tem sinal positivo; assim, aqueles indivíduos que tiveram o privilégio de nascer em famílias mais abastadas têm mais chances no vestibular, além de poderem almejar cursos mais concorridos e que pagam uma renda vitalícia maior. Esta variável permite concluir que a educação superior é um mecanismo de transferência intergeracional da riqueza. O capital físico pode ser transferido de uma geração para a outra diretamente, estando essa transferência, porém, sujeita a algum tipo de tributação. No caso da educação, sendo esta uma forma de capital humano incorporado nas pessoas, a escola intermedeia a transferência da riqueza. Em se tratando de uma universidade pública e gratuita, essa transferência ocorre sem o pagamento de qualquer tributo ou mensalidade.

Calculou-se, a partir das datas de realização do vestibular e de conclusão do ensino médio, a variável "tempo de conclusão do ensino médio"; essa variável, medida em logaritmos, mostrou-se estatisticamente significativa e o seu coeficiente apresentou-se positivo, contrariando o que se esperava. Constatando-se a sua alta correlação com a variável idade

12 A correlação estatística entre as variáveis $\ln (\mathrm{tq})$ e $\ln [\mathrm{A}(\mathrm{D}-\mathrm{S})]$ é igual a -0.182 , o que indica que quanto mais o indivíduo trabalha, menor o escore mínimo esperado. 
(também medida em logaritmos), resolveu-se então pela sua exclusão na regressão final da Tabela 1.

O tempo tq afeta negativamente o escore do candidato, como era de se esperar, pois quanto menos tempo se tem para estudar, menor o escore. O coeficiente dessa variável é a elasticidade cruzada do tempo alocado à produção de $\mathrm{Q}$ com respeito ao escore no vestibular. Essa elasticidade é de 0,0497, em valor absoluto. Assim, a cada $10 \%$ de aumento em tq, o escore reduz-se, em média, aproximadamente, de $0,5 \%$.

Uma outra variável que demonstra as maiores dificuldades de acesso ao ensino superior dos alunos pobres e negros ${ }^{13}$, em geral, é a variável que informa sobre a educação pregressa do candidato: o aluno que estudou em escola de ensino médio pública ou na maior parte do tempo nesse tipo de escola, tem uma redução média de cerca de 1,02\% no seu escore em comparação aos alunos provenientes das escolas particulares; além disso, se a residência atual do candidato é na capital, o escore é, em média, 3,7\% superior ao daquele que reside, atualmente, no interior ou em outro estado.

Todas as variáveis remanescentes na Tabela 1 sobre a ocupação da mãe indicam que o desempenho do candidato é inferior comparativamente à mãe que não trabalha, sendo esse efeito menor quando a mãe é professora de $1^{\circ}$ ou $2^{\circ}$ grau ou quando a ocupação dela é industrial qualificada; entretanto, quando o nível de educação da mãe do candidato é superior, o escore é maior em 1,71\%, em média, se comparado à mãe que tem o curso superior incompleto ou menos.

A ocupação de técnico em geral, seja do pai ou do próprio candidato, impacta favoravelmente o escore em cerca de 1,2\%; além disso, se a ocupação do pai é de capitalista (dono de empresa de grande, médio ou pequeno porte) ou gerente, o escore do candidato também é superior em $0,37 \%$, em média, em comparação com aquele pai que não trabalha. Mas a variável "Se o candidato é capitalista ou gerente" não é estatisticamente significativa, sendo excluída da análise.

Ademais, se a educação do pai é superior completa, isto afeta positivamente o escore do candidato em $1,07 \%$; se o pai é professor de $1^{\circ}$ ou $2^{\circ}$ grau, isto impacta positivamente o escore do candidato em $0,8 \%$, em média. Mas, se o pai é militar ou atleta, o escore do candidato é inferior em $0,6 \%$, aproximadamente, em média.

Aqueles candidatos que acreditam que o cursinho ensina "macetes" apresentam um desempenho inferior em 5,4\%, em média; além disso, o aluno que faz cursinho apresenta um desempenho inferior em $0,8 \%$, em

13 A variável relativa à etnia não se encontra disponível nas bases de dados utilizadas. 
média; isto talvez indique que a educação baseada em "macetes" e "decoreba" não é a mais eficaz enquanto o vestibular procure avaliar mais a capacidade de análise e síntese do candidato, ou, então, que o candidato que procura um cursinho é menos hábil ou preparado.

$\mathrm{O}$ aluno que fez o curso colegial ou técnico tem um escore superior em cerca de 4,9\% e 1,2\%, respectivamente, em comparação àquele que fez o supletivo ou magistério; o escore do candidato do sexo masculino é cerca de $2 \%$ superior ao do sexo oposto, em média ${ }^{14}$. Outrossim, o aluno solteiro tem um escore de quase $9 \%$ inferior, em média, ao aluno não solteiro. Enquanto o resultado dos sexos é curioso, mas esperado, pois outros estudos indicam o mesmo resultado (Soares, Fonseca, 1998), o relativo ao estado civil é esperado: o candidato não solteiro tem uma maior carga de responsabilidade, dedicando-se mais aos estudos.

Se o candidato mora com famílias ou parentes, o seu escore é 1,25\% inferior em média. Além disso, se o candidato não é responsável pelo próprio sustento, o que indica sua menor responsabilidade, o seu escore também é inferior em 1,07\%, em média. Porém, se o candidato é professor de $1^{\circ}$ ou $2^{\circ}$ grau o seu escore é superior em quase $3 \%$, em média.

Das variáveis relativas ao trabalho do candidato, as remanescentes na regressão da Tabela 1 mostraram-se com coeficientes negativos, impactando desfavoravelmente o escore no vestibular. Destas variáveis, a que menos impacto negativo oferece é a que diz respeito ao candidato que trabalha e se sustenta, seguido pelo candidato que trabalha apenas pelo turno da manhã.

Quanto mais experiente o candidato em provas vestibulares, maiores são as suas chances de ingresso, demonstrando que o candidato aprende com a experiência, inclusive, eventualmente, com os insucessos passados. A cada vez que o candidato tenta, o seu escore se eleva em 1,7\%.

A variável "Se o curso escolhido é da área 2" foi excluída por ter uma correlação negativa e alta com os cursos da área 3. Os cursos da área 2 são Medicina, Odontologia, Enfermagem e Obstetrícia. Os cursos da área 3 apresentaram um escore médio superior em $2,2 \%$ se comparado ao escore dos candidatos da área 5 , que corresponde à variável omitida. Os cursos da área 3 são tradicionalmente concorridos; essa área é formada por Administração de Empresas, Comunicação, Direito, Psicologia e Economia.

Revela-se, também, que o interesse pessoal, seja de caráter econômico ou por status social, é bastante significativo, porém o seu efeito é

14 É curioso este resultado por sexo. No caso do mercado de trabalho, evidencia-se uma discriminação por gênero, que não haveria de ser o caso do vestibular; uma possível razão para isto, mas que precisa ser investigada, é se a mulher estaria se encaminhando, em maior proporção, para os cursos que exigem um escore mínimo menor. 
negativo; o candidato motivado por esses fatores tem um escore médio inferior em 9,2\%; além disso, se o candidato declara que ninguém ou nada influenciou em sua decisão, o seu escore é reduzido em cerca de $1 \%$, em média. Porém, se o candidato acha a sua escolha do curso adequada à sua aptidão, o seu escore é superior em cerca de 1,8\% em média.

A última variável é o tempo; esta variável foi construída subtraindose do ano em que o candidato fez o vestibular o ano de 1993 por ser este o primeiro ano da base. Assim, essa variável assumiu os valores 0,1 e 2 . O coeficiente dessa variável, altamente significativa, revela que a cada ano que passa os escores médios se reduzem em cerca de $8,1 \%$. As razões para isto poderiam estar em que as provas vestibulares têm se tornado mais difíceis, o nível acadêmico dos alunos tem se reduzido, ou ambos.

Outras estatísticas da regressão da Tabela 1 são que o coeficiente de determinação múltipla foi elevado e igual a 45,2\%, em amostra de 64.319 candidatos dos anos de 1993, 1994 e 1995;e, ademais, a estatística F de 1.326,23 é altamente significativa.

\section{RESULTADOS DO SISTEMA DE EQUAÇÕES}

O Quadro 1 permite calcular a média da distribuição da razão ta/tq [equação (25)] de uma amostra de 87.271 observações; essa média corresponde a 0,4465 com desvio-padrão igual a 0,1582. Isto permite formar o sistema (28) de cinco equações, seis incógnitas e as restrições quanto às incógnitas:

$$
\begin{aligned}
& {[(1-\mathrm{a}) \cdot \varepsilon / \mathrm{\alpha}]^{2} \cdot(1 / \varphi)=0,0497} \\
& {[\alpha \cdot \varphi / \varepsilon(1-\alpha)]+(\mathrm{h} / \mathrm{tq})=0,4465} \\
& \mathrm{ta}-[\alpha \cdot \varphi / \varepsilon .(1-\mathrm{\alpha})] \cdot \mathrm{tq}=\mathrm{h} \\
& \mathrm{ta} / \mathrm{tq}=0,4495 \\
& \mathrm{ta}+\mathrm{tq}=168 \quad(\text { da resolução do Teorema de Kuhn-Tucker) } \\
& \mathrm{h}>0,0<\varepsilon<1,0<\varphi<1,0<\mathrm{\alpha}<1,20,5 \leq \mathrm{ta} \leq 60,5 \text { e } 107,5 \leq \mathrm{tq} \leq 147,5
\end{aligned}
$$

Na primeira equação do sistema (28) tem-se o coeficiente estimado da variável lntq da Tabela 1 (Anexo). A segunda equação foi obtida dividindo-se a equação (25) por tq. 
Simplificando-se o sistema (28), obtém-se o sistema (29):

$$
\begin{aligned}
& {[(1-a) \cdot \varepsilon / a]^{2} \cdot(1 / \varphi)=0,0497} \\
& {[\alpha \cdot \varphi / \varepsilon(1-a)]+\left(h / \mathrm{tq}^{*}\right)=0,4465} \\
& \text { ta }^{*}-[a \cdot \varphi / \varepsilon \cdot(1-\mathrm{a})] \cdot \mathrm{tq}^{*}=\mathrm{h} \\
& \mathrm{h}>0,0<\varepsilon<1,0<\varphi<1,0<\mathrm{a}<1 .
\end{aligned}
$$

Da resolução, ta $^{*}=51,8575873$ e tq ${ }^{*}=116,1424127$, onde ta* e tq* são as quantidades ótimas de alocação do tempo para o estudo e para a produção de $Q$, respectivamente, na média de todos os candidatos da amostra ( $n=87.271)$. Este sistema admite uma infinidade de soluções, mas levantando-se hipóteses a respeito do valor de a, determinam-se algumas soluções possíveis e mais prováveis. Os resultados encontram-se na Tabela 3 , anexa.

Como se pode observar na Tabela 3, $\varphi$ é constante e igual a 0,99\% para todos os valores de a para os quais foram feitas hipóteses; $\varepsilon$ é crescente com a e inferior a $\varphi$ para valores no intervalo $0,1 \leq \alpha \leq 0,3$. Se se considerar que seja mais provável que a capacidade de transformar o tempo tq em $Q$ deva ser maior do que a capacidade de transformar o tempo de estudo ta em $\mathrm{A}($. ), os valores da Tabela 3 mais verossímeis devem ser aqueles para os quais $\alpha \geq 0,4$. No entanto, à medida que $\alpha$ se aproxima de $0,9, \varepsilon$ se torna mais de 20 vezes superior a $\varphi$, o que leva ao questionamento desses valores mais elevados. Quaisquer que sejam esses valores, no entanto, o indivíduo maximiza a sua utilidade, pois $\theta_{2}$ é positivo.

Outrossim, observe-se na Tabela 3 que o indivíduo aloca otimamente quase 52 horas semanais para o estudo, na média dos candidatos, considerando que $37,8 \%$ deles trabalha [pois $62,2 \%$ dos candidatos não trabalham segundo a equação (13)]; considerando as demais alocações de tempo do Quadro 1, restaria muito pouco tempo disponível para o trabalho, apenas 8,5 horas. Assim, o candidato que trabalha porque precisa, caso não consiga ajustar o seu tempo, procurará um curso que exija menor habilidade de transformar horas de estudo em escores no vestibular; o curso escolhido, além de ser um curso de menor preferência, será também um curso que, depois de concluído (se o for), não proporcionará a mobilidade social que o candidato precisa. 


\section{CONCLUSÕES}

O modelo teórico sugere que o candidato ao vestibular, sob o pressuposto de um comportamento racional, realiza uma auto-seleção do curso a que vai concorrer. Essa decisão, a despeito de ser do indivíduo, é influenciada pelas suas condições psico-econômico-sociais e pela sua própria história familiar e escolar pregressa. Com efeito, o candidato que tem menor disponibilidade de tempo para o estudo, porque precisa trabalhar, tende a escolher um curso menos concorrido para maximizar a sua utilidade total; além disso, o candidato leva em consideração as suas habilidades e preferências; ademais, se ele provém de família de maior renda, provavelmente teve acesso mais amplo a bens culturais, a mais informação etc., que promovem um melhor desempenho escolar.

Como resultado dessas decisões individuais, o vestibular se mostra como um mecanismo de perpetuação da condição socioeconômica do indivíduo na medida em que os cursos mais concorridos são aqueles que proporcionarão uma renda vitalícia maior; no agregado do conjunto dos candidatos aprovados, reproduz-se a própria estrutura de classes da sociedade. Acredita-se que os modelos desenvolvidos neste trabalho explicam satisfatoriamente o porquê de haver uma predominância tão grande de estudantes provenientes dos estratos sociais mais elevados nos cursos de maior prestígio e uma predominância tão grande de estudantes de estratos sociais mais baixos nos cursos de menor prestígio.

A estratégia utilizada de se verificar a correlação estatística por meio de análise de regressão evidencia que a seletividade social do vestibular de fato ocorre. Essa evidência se caracterizou quando se utilizou o escore mínimo para ser aprovado em um curso (supondo-se que este fosse o mesmo esperado pelo candidato) como variável dependente e o excesso de demanda por cada curso, além de um conjunto de variáveis sobre a família e o próprio candidato como variáveis de controle. Outras estratégias empíricas poderiam ser utilizadas por meio de modelos logit ou probit ordenado. Mas isto ficou para um trabalho posterior.

Os principais resultados, a partir da estimação da função de produção educacional com o logaritmo do escore final efetivo como variável dependente, são de que o indivíduo mais pobre (observando-se a sua renda familiar) e que é, geralmente, proveniente de escola pública, têm escores médios mais reduzidos.

O nível de instrução superior dos pais se mostrou significativo e impacta positivamente o escore no vestibular, em comparação aos pais em que a educação é menor do que o superior completo. Ademais, quanto 
maior a idade do indivíduo, menor o escore do candidato, o que se explica pela depreciação do estoque de conhecimentos do candidato.

Feitas essas considerações, proponho que a Universidade pública seja gratuita apenas para os indivíduos comprovadamente pobres; além disso, que a receita proveniente dos indivíduos não-pobres seja destinada à concessão de uma bolsa de estudos aos candidatos pobres aprovados, para que possam estudar em tempo integral, sem a necessidade de trabalharem. Com isto, os candidatos pobres se sentirão mais encorajados para escolher os cursos mais concorridos, que são os cursos de maior prestígio e que pagam, durante a vida laboral do indivíduo, uma renda vitalícia maior; além disso, se estará possibilitando que o aluno carente conclua o seu curso superior, pois o fator econômico pesa na decisão de se abandonar um curso. Como conseqüência, a universidade pública estará contribuindo para que haja uma maior mobilidade social no Brasil e estará se fazendo justiça social.

Uma outra razão de caráter econômico para que se cobre a mensalidade daqueles que podem pagar é que, ao se instituir um custo ao aluno rico, a sua taxa de retorno na educação superior se reduzirá, tendendo a se equiparar à do aluno pobre. Isto deverá contribuir para uma maior igualdade de renda futura; além disso, a universidade pública precisa diversificar as suas fontes de financiamento, haja vista a crise fiscal das universidades e do Estado brasileiro.

Esta proposta vai ao encontro do sugerido por Camargo (1999); segundo esse autor, para se resolver o problema da pobreza é preciso atacálo em duas frentes: a curto prazo, desenhando-se programas de transferência de renda do rico para o pobre; e, a longo prazo, aumentandose o estoque de capital humano do pobre.

\section{REFERÊNCIAS BIBLIOGRÁFICAS}

AKIN, J.S.; STEWART, J.F. The Time-Allocation Decision and Achievement Patterns of Young Children. Economics of Education Review, v.2, n.4, 1982. p.307-330.

AVENA, C.P. Demanda por ensino superior: o caso da Universidade Federal da Bahia. Estudos em Avaliação Educacional, n.29, jan-jun/2004. p.111-136. 
Os Retornos do Capital Humano na Região Metropolitana de Salvador. Salvador, 2000. Dissertação (mestr.) Universidade Federal da Bahia/Curso de Mestrado em Economia, 116p.

BLOOM, B.S. Human Characteristics and School Learning. New York: McGraw-Hill Company, 1976, 284p.

BOWLES, S.; GINTIS, H. The Inheritance of Inequality. Journal of Economic Perspectives, v.16, n. 3, Summer 2002. p. 3-30.

CAMARGO, J.M. Mãos à obra, senador! Folha de São Paulo, São Paulo, 11 de agosto de 1999, Caderno Opinião, Tendências e Debates.

CARRERA-FERNANDEZ, J. Microeconomia. CME/UFBA, 1998. (mimeo)

DOLTON, P.; MARCENARO, O.D.; NAVARRO, L. The effective use of student time: stochastic frontier production function case study. Economics of Education Review, XX, 2003.

GREEN, W.H. Econometric Analysis. 4th. Ed. New Jersey: Prentice Hall, 2000, 1004 p.

JUSSIM, L. Teacher Expectations: Self-Fulfilling Prophecies, Perceptual Biases, and Accuracy. Journal of Personality and Social Psychology, v. 57, n.3, 1989. p.469-480.

KREPS, D.M. A Course in Microeconomic Theory. New Jersey: Princeton University Press, 1990, 839p.

LEVIN, H.M.; TSANG, M.C. The Economics of Student Time. Economics of Education Review, v.6, n. 4, 1987. p.357-364.

MAS-COLELL,A.; WHINSTON, M.D.; GREEN, J.R. Microeconomic Theory. Oxford: Oxford University Press, 1995, 981p.

MINISTÉRIO DA EDUCAÇÃO (Inep). Mapa da Educação Superior no Brasil. Brasília, março 2004.

ROSENTHAL, R.; JACOBSON, L. Pygmalion in the Classroom. Teacher Expectation and Pupil's Intellectual Development. Williston, VT: Crown House Publishing Limited, 1992, 266p. 
SOARES, J.F.; CASTRO, C.M.; CÉSAR, C.C. Escolas de Ensino Médio de Belo Horizonte: As Campeãs e as que oferecem mais ao Aluno. Ensaio: aval.pol.públ.Educ., v.10, n.34, jan./mar.2002. p.101-122.

SOARES, J.F.; FONSECA, J.A. Fatores Socioeconômicos e o Desempenho no Vestibular da UFMG-97. UFMG/Depto. de Estatística, 1998. 30p. (mimeo)

SOUZA, A. de M. Determinantes da Escolarização na Cidade do Rio de Janeiro. In: Financiamento da Educação e Acesso à Escola no Brasil. Rio de Janeiro: IPEA/INPES, 1979. p.107-154.

TODD, P.E.; WOLPING, K.I. On the Specification and Estimation of the Production Function for Cognitive Achievement. University of Pennsylvania, 2001. (mimeo)

VARIAN, H. R. Microeconomic Analysis, $2^{\text {nd }}$ Ed. New York: W.W. Norton \& Co, 1984, 350p.

Recebido em: outubro 2003 Aprovado para publicação em: setembro 2004 


\section{ANEXOS}

Tabela 1: Estimativas da equação (27) com LnA[tq, A(D-S), Id, R, X] como variável dependente

\begin{tabular}{|c|c|c|c|c|}
\hline Variáveis & $\begin{array}{l}\text { Coeficientes não } \\
\text { padronizados } \\
\text { (B) }\end{array}$ & $\begin{array}{c}\text { Coeficientes } \\
\text { padronizados } \\
\text { (Beta) }\end{array}$ & Estatística $t$ & Sig. \\
\hline Intercepto & 7.242 & & 100.985 & 0.000 \\
\hline Lntq & $-4.97 \mathrm{E}-02$ & -0.035 & -7.012 & 0.000 \\
\hline Ln (escore mínimo) & 0.473 & 0.348 & 103.151 & 0.000 \\
\hline Ln (idade) & -0.113 & -0.131 & -27.086 & 0.000 \\
\hline Ln (renda familiar) & $1.05 \mathrm{E}-02$ & 0.06 & 18.271 & 0.000 \\
\hline Número de vezes que prestou concurso Vestibular & $1.70 \mathrm{E}-02$ & 0.122 & 34.568 & 0.000 \\
\hline Se a educação da mãe é superior completo* & 1.71E-02 & 0.044 & 13.594 & 0.000 \\
\hline Se a educação dos pai é superior completo* & 1.07E-02 & 0.01 & 3.467 & 0.001 \\
\hline $\begin{array}{l}\text { Se a escolha foi baseada em interesse pessoal (econômico } \\
\text { ou social)* }\end{array}$ & $-9.21 \mathrm{E}-03$ & -0.017 & -4.651 & 0.000 \\
\hline Se a mãe é capitalista ou gerente & $-1.11 \mathrm{E}-02$ & -0.02 & -6.223 & 0.000 \\
\hline Se a mãe é militar ou atleta* & $-2.94 \mathrm{E}-02$ & -0.012 & -3.889 & 0.000 \\
\hline Se a mãe é professora de $1^{\circ}$ ou de $2^{\circ} \operatorname{grau}^{*}$ & $-3.36 \mathrm{E}-03$ & -0.009 & -2.634 & 0.008 \\
\hline Se a ocupação da mãe é "outras" * & $-1.10 \mathrm{E}-02$ & -0.029 & -8.852 & 0.000 \\
\hline Se a ocupação da mãe é industrial qualificada* & $-5.61 \mathrm{E}-03$ & -0.008 & -2.504 & 0.012 \\
\hline Se a ocupação do candidato é de técnicos em geral* & 1.27E-02 & 0.021 & 6.285 & 0.000 \\
\hline Se a ocupação do pai é de técnico em geral ${ }^{*}$ & 1.17E-02 & 0.03 & 8.954 & 0.000 \\
\hline Se fez cursinho preparatório para o vestibular* & $-8.08 \mathrm{E}-03$ & -0.025 & -7.305 & 0.000 \\
\hline $\begin{array}{l}\text { Se fez o ensino médio em escola pública ou na maior parte } \\
\text { pública }\end{array}$ & $-1.02 \mathrm{E}-02$ & -0.031 & -8.132 & 0.000 \\
\hline Se o candidato acha a escolha adequada às aptidões* & 1.77E-02 & 0.047 & 13.111 & 0.000 \\
\hline Se o candidato acredita que o cursinho dá "macetes"* & $-5.37 \mathrm{E}-03$ & -0.012 & -3.481 & 0.000 \\
\hline $\begin{array}{l}\text { Se o candidato considera que ninguém ou nada } \\
\text { influenciou na escolha do curso* }\end{array}$ & $-1.02 \mathrm{E}-02$ & -0.032 & -10.842 & 0.000 \\
\hline Se o candidato é do sexo masculino* & $2.00 \mathrm{E}-02$ & 0.062 & 19.337 & 0.000 \\
\hline Se o candidato é professor de $1^{\circ}$ ou $2^{\circ}$ grau $^{*}$ & $2.94 \mathrm{E}-02$ & 0.035 & 10.713 & 0.000 \\
\hline Se o candidato é solteiro* & $-8.98 \mathrm{E}-03$ & -0.015 & -4.132 & 0.000 \\
\hline Se o candidato escolheu um curso da área $1^{*}$ & $-6.00 \mathrm{E}-03$ & -0.015 & -4.313 & 0.000 \\
\hline Se o candidato escolheu um curso da área $3^{*}$ & 2.17E-02 & 0.067 & 19.685 & 0.000 \\
\hline Se o candidato escolheu um curso da área $4^{*}$ & $3.18 \mathrm{E}-02$ & 0.033 & 10.834 & 0.000 \\
\hline Se o candidato fez o curso colegial ${ }^{*}$ & $4.88 \mathrm{E}-02$ & 0.152 & 28.516 & 0.000 \\
\hline Se o candidato fez o curso técnico* & 1.17E-02 & 0.034 & 7.026 & 0.000 \\
\hline Se o candidato foi aprovado* & 0.19 & 0.434 & 74.223 & 0.000 \\
\hline $\begin{array}{l}\text { Se o candidato foi matriculado no } 1^{\circ} \text { semestre do ano em } \\
\text { que foi aprovado }\end{array}$ & $2.48 \mathrm{E}-02$ & 0.051 & 8.704 & 0.000 \\
\hline Se o candidato mora com família ou parentes ${ }^{*}$ & $-1.25 \mathrm{E}-02$ & -0.02 & -6.683 & 0.000 \\
\hline Se o candidato não é responsável pelo próprio sustento* & $-1.07 \mathrm{E}-02$ & -0.016 & -4.393 & 0.000 \\
\hline Se o candidato trabalha e recebe ajuda* & $-1.11 \mathrm{E}-02$ & -0.025 & -6.126 & 0.000 \\
\hline Se o candidato trabalha e se sustenta* & $-8.05 \mathrm{E}-03$ & -0.012 & -3.564 & 0.000 \\
\hline Se o candidato trabalha pela manhã ${ }^{*}$ & $-4.88 \mathrm{E}-03$ & -0.007 & -2.333 & 0.020 \\
\hline Se o local de residência atual do candidato é na capital ${ }^{*}$ & $3.69 \mathrm{E}-02$ & 0.079 & 26.089 & 0.000 \\
\hline Se o pai do candidato é capitalista ou gerente* & $3.72 \mathrm{E}-03$ & 0.01 & 2.838 & 0.005 \\
\hline Se o pai é militar ou atleta* & $-5.68 \mathrm{E}-03$ & -0.008 & -2.563 & 0.010 \\
\hline Se o pai é professor de $1^{\circ}$ ou de $2^{\circ}$ grau $^{*}$ & $7.81 \mathrm{E}-03$ & 0.006 & 2.011 & 0.044 \\
\hline Tempo (Ano do concurso - 1993) & $-8.09 \mathrm{E}-02$ & -0.041 & -13.904 & 0.000 \\
\hline
\end{tabular}

Fonte: Cálculos do autor a partir das bases de dados do vestibular.

$$
\mathrm{R}^{2}=45,2 \% \text { (Erro-padrão = 0,1178), } \mathrm{n}=64.319 \text { e } \mathrm{F}=1.326,23(\mathrm{Sig}=0,0 \% \text { ) }
$$


Tabela 2: Estimativas da equação (27) com $\operatorname{LnA}[(\mathrm{D}-\mathrm{S}), \mathrm{tq}, \mathrm{Id}, \mathrm{R}, \mathrm{X}]$ como variável dependente

\begin{tabular}{|c|c|c|c|c|}
\hline Variáveis & $\begin{array}{l}\text { Coeficientes não } \\
\text { padronizados } \\
\text { (B) }\end{array}$ & $\begin{array}{l}\text { Coeficientes } \\
\text { padronizados } \\
\text { (Beta) }\end{array}$ & Estatística t & Sig. \\
\hline Intercepto & 12.803 & & $1.142,96$ & 0.000 \\
\hline $\operatorname{Ln}(\mathrm{tq})$ & $-8.13 \mathrm{E}-03$ & -0.008 & -3.468 & 0.001 \\
\hline Ln (excesso de demanda) & 0.106 & 1.002 & 463,58 & 0.000 \\
\hline Ln (idade) & $-1.96 \mathrm{E}-02$ & -0.033 & -14.085 & 0.000 \\
\hline Ln (renda familiar) & $2.65 \mathrm{E}-03$ & 0.021 & 11.435 & 0.000 \\
\hline Se a educação da mãe é superior completo* & 2.74E-03 & 0.009 & 5.069 & 0.000 \\
\hline Se a educação do pai é superior completo* & 3.77E-03 & 0.005 & 2.900 & 0.004 \\
\hline Se a escola de ensino médio foi na capital ${ }^{*}$ & $-1.62 \mathrm{E}-03$ & -0.006 & -3.478 & 0.001 \\
\hline Se a ocupação da mãe é "outras" * & $-1.96 \mathrm{E}-03$ & -0.007 & -4.118 & 0.000 \\
\hline Se a ocupação da mãe é industrial qualificada* & $-2.48 \mathrm{E}-03$ & -0.005 & -2.736 & 0.006 \\
\hline Se a ocupação do candidato é de técnicos em geral* & $4.28 \mathrm{E}-03$ & 0.01 & 5.244 & 0.000 \\
\hline Se a ocupação do candidato é em serviços* & $-2.04 \mathrm{E}-03$ & -0.004 & -2.385 & 0.017 \\
\hline Se a ocupação do pai é de técnico em geral ${ }^{*}$ & $2.84 \mathrm{E}-03$ & 0.009 & 5.388 & 0.000 \\
\hline Se a ocupação do pai é industrial qualificada* & $1.30 \mathrm{E}-03$ & 0.004 & 2.387 & 0.017 \\
\hline $\begin{array}{l}\text { Se fez o ensino médio em escola pública ou na maior parte } \\
\text { pública }\end{array}$ & $-1.55 \mathrm{E}-03$ & -0.006 & -3.080 & 0.002 \\
\hline Se o candidato é do sexo masculino* & 1.63E-02 & 0.068 & 38,14 & 0.000 \\
\hline Se o candidato escolheu um curso da área $1^{*}$ & -0.129 & -0.434 & -83.688 & 0.000 \\
\hline Se o candidato escolheu um curso da área $2^{*}$ & -0.181 & -0.71 & $-111,343$ & 0.000 \\
\hline Se o candidato escolheu um curso da área $3^{*}$ & -0.209 & -0.867 & $-130,60$ & 0.000 \\
\hline Se o candidato escolheu um curso da área $4^{*}$ & -0.141 & -0.208 & -77.812 & 0.000 \\
\hline Se o candidato fez cursinho pré-vestibular* & $2.54 \mathrm{E}-03$ & 0.011 & 6.348 & 0.000 \\
\hline Se o candidato fez o curso colegial ${ }^{*}$ & 1.83E-02 & 0.077 & 27,203 & 0.000 \\
\hline Se o candidato fez o curso técnico* & 1.34E-02 & 0.053 & 20.569 & 0.000 \\
\hline $\begin{array}{l}\text { Se o candidato foi matriculado no } 2^{\circ} \text { semestre do ano em } \\
\text { que foi aprovado* }\end{array}$ & $-2.52 \mathrm{E}-02$ & -0.035 & -20.951 & 0.000 \\
\hline Se o candidato mora com família ou parentes* & $-4.36 \mathrm{E}-03$ & -0.01 & -5.814 & 0.000 \\
\hline Tempo (Ano do concurso - 1993) & $-1.16 \mathrm{E}-02$ & -0.078 & -45.967 & 0.000 \\
\hline
\end{tabular}

Fonte: Cálculos do autor a partir da base de dados do vestibular.

$\mathrm{R}^{2}=78,4 \%, \mathrm{n}=80.443$ e $\mathrm{F}=11.222,51(\mathrm{Sig}=0,0 \%)$

Tabela 3: Estimativas dos coeficientes considerando ta $+\mathrm{t} q=168$ horas

\begin{tabular}{|c|c|c|c|c|c|c|c|c|c|}
\hline $\begin{array}{l}\text { Coeficientes } \\
\text { estimados }\end{array}$ & & & & Alguns d & os Valores & Possíveis & & & \\
\hline$\alpha$ & 0.1 & 0.2 & 0.3 & 0.4 & 0.5 & 0.6 & 0.7 & 0.8 & 0.9 \\
\hline $\mathrm{h}$ & 8E-09 & $1 \mathrm{E}-08$ & $5 \mathrm{E}-06$ & $2 \mathrm{E}-08$ & 2.3E-06 & 2E-07 & $5 \mathrm{E}-08$ & $1 \mathrm{E}-05$ & 1.3E-06 \\
\hline$\varepsilon$ & $0.25 \%$ & $0.55 \%$ & $0.95 \%$ & $1.48 \%$ & $2.22 \%$ & $3.33 \%$ & $5.18 \%$ & $8.88 \%$ & $19.97 \%$ \\
\hline$\varphi$ & $0.99 \%$ & $0.99 \%$ & $0.99 \%$ & $0.99 \%$ & $0.99 \%$ & $0.99 \%$ & $0.99 \%$ & $0.99 \%$ & $0.99 \%$ \\
\hline $\mathrm{tq}$ & 116.14 & 116.14 & 116.14 & 116.14 & 116.142 & 116.14 & 116.14 & 116.14 & 116.142 \\
\hline ta & 51.858 & 51.858 & 51.858 & 51.858 & 51.8576 & 51.858 & 51.858 & 51.858 & 51.858 \\
\hline$\theta_{2}$ & positivo & positivo & positivo & positivo & positivo & positivo & positivo & positivo & positivo \\
\hline
\end{tabular}

Fonte: Cálculos do autor a partir da Tabela 1 e de valores do sistema de equações (29).. 
